\title{
A profissão docente à prova da Nova Gestão Pública: a reforma inglesa da Terceira Via
}

Teacher Profession under questioning of New Public Management: the Third Way British reform

Romuald Normand

Escola Normal Superior de Lyon

Instituto Francês de Educação

\section{Resumo}

artigo tem como objetivo discutir a profissão docente sob as políticas da Nova Gestão Pública no contexto da reforma inglesa implementada pelalógica da Terceira Via. Com base na teoria política que analisa criticamente as políticas gerencialistas em educação, o texto discute a reestruturação da profissão docente imposta pela gestão centrada no desempenho, analisando a reestruturação de funções e recomposição desse novo profissionalismo. Por fim, o autor confronta as características dessas reformas com as mudanças ocorridas na França, demonstrando similaridades e diferenças em cada contexto, mas ressalta que as transformações na profissão docente em ambos os contextos possuem a mesma natureza política.

Palavras-chave: Profissão docente. Nova gestão pública. Terceira via.

\section{Abstract}

This article aims at discussing teacher profession under New Public Management policies in the context of the Third Way British reform. Based on a political theory that intends to analyze critically managerial policies in education, this paper discusses a restructuring of teacher profession imposed by a performative managerial policy, demonstrating how changes have been done and what is the new reconfiguration of this new professionalism. Lastly, the author confronts some particularities of this reform with some changes that occurred in France, demonstrating similarities and differences of each context, but highlighting that changes in teacher profession in both contexts are under same political logics. Keywords: Teacher profession. New public management. Thirdway. 
Na Inglaterra, a identidade da profissão docente é definida em relação a um sistema de escola compreensiva inventada pelo partido trabalhista. Ela foi consequência de uma importante mobilização de ativistas educacionais e da esquerda política para pôr fim à seleção precoce dos alunos, instituir um tronco comum e promover métodos pedagógicos ativos no ensino secundário. Nos anos 1960-1970, este modelo profissional tornou-se referência para muitos países engajados nas políticas de democratização do acesso ao ensino secundário e superior. Hoje esta forma de organização do trabalho pedagógico é requestionada sob o efeito das reformas inspiradas pelos princípios da Nova Gestão Pública - New Public Management. (BEZES, 2009; POLlIT, BOUCKAERT, 2004). A política iniciada por Tony Blair e seu governo constitui uma boa ilustração deste processo.

A Terceira Via é considerada um campo de experiências do Nova Gestão Pública na educação como em outras áreas de ação pública. ICLARKE, J., GEWIRTZ, S., MC LAUGHIN, E., 2000; DEROUET, NORMAND, 2011 la; FAUCHER-KING E LE GALĖS, 2010; NORMAND,20111. A França não está fora dessas evoluções, são perceptíveis mudanças nos modos de governo do sistema educativo (liberalização do mapeamento escolar, nova política de educação prioritária centrada em resultados, implementação da $\mathrm{LOLF}^{1}$ e difusão de uma cultura de desempenho) e no trabalho dos professores (base comum de conhecimento e competência, contrato de metas entre as instituições, conselho pedagógico para favorecer o trabalho em equipe). Frente a esses desafios, é fácil afirmar que a profissão docente está ameaçada em sua identidade profissional, que ela encara um processo inevitável de desqualificação e de desprofissionalização. Estimo que esta reforma corresponda a uma mudança de modelo profissional que institui novas regras do trabalho, recompondo a organização do trabalho na escola. Ela transforma os mecanismos de controle que se apoiam menos sobre uma ordem burocrática e mais sobre a avaliação de atividades e de pessoas. Isto pode gerar derivas como uma pressão ao desempenho e à eficácia induzida por uma obrigação cega de resultados que prejudica o surgimento de um novo profissionalismo. Esta nova regulação, no entanto, também tem efeitos positivos em relação à definição de responsabilidades, ao reconhecimento das competências, às concepções de ensino e de aprendizagem, ao compartilhamento de informação. Ela cria, certamente, novas normas de socialização e de integração profissional, mas também novos espaços de autonomia e de subjetivação para os docentes. (DUBET, 2009). 
A partir de uma série de exemplos obtidos da experiência inglesa, evoco as tendências que recompõem progressivamente os modos de afiliação, a identidade profissional e as fronteiras do exercício da profissão docente.

Apontarei algumas das críticas feitas por sociólogos a este modo de organização do trabalho centrado no desempenho, no controle de gastos, na busca pela eficiência. Primeiramente, descrevo os efeitos deste novo regime de desempenho sobre a reestruturação da profissão docente inglesa. Após, mostro como a Nova Gestão Pública transformou a divisão dos papéis e as responsabilidades dos docentes na escola, assim como as condições de ingresso na profissão e a formação. Concluindo, estabeleço alguns pontos de comparação com a situação francesa e as atuais reformas.

\section{A profissão docente reestruturada pela gestão do desempenho}

A profissão docente inglesa, decisivamente colocada na lista negra pela Nova Direita, teve sua cultura e sua identidade profissional testadas no início dos anos 1980. Os direitos à negociação coletiva foram suprimidos e as condições de remuneração e de evolução de carreira foram revisadas. Os sindicatos docentes opuseram-se ao fortalecimento do controle sobre a profissão, ao aumento do tempo de trabalho e à individualização dos percursos profissionais. Mas eles não conseguiram impedir esse movimento de reestruturação. Ao mesmo tempo, tomava lugar uma gestão de desempenho que buscava dois objetivos: a excelência das escolas e o desenvolvimento da concorrência para melhorar a qualidade das mesmas. A avaliação transparente dos resultados dos alunos devia orientar a escolha das famílias e contribuir para melhor dividir os recursos públicos. A definição dos conteúdos ensinados era centralizada e confiada a uma agência nacional que estabelecia os padrões a serem atingidos (standards). A pedagogia na sala de aula estava alinhada aos testes aplicados aos alunos. $\bigcirc$ diretor da escola assumia funções de gestão e prestava contas de sua ação a conselhos administrativos com poderes ampliados, envolvendo pais de alunos e empresas.

As reações às reformas foram muito diferentes entre os docentes, embora eles compartilhassem um mesmo sentimento de anomia e de desprofissionalização. (MAC AN GHAlLL, 1992). Por um lado, os docentes "militantes", membros de sindicatos e próximos ao partido trabalhista, opunham-se 
ferozmente às reformas e às mudanças de suas condições de trabalho. Eles protestavam contra a criação de funções intermediárias na escola e permaneciam sensíveis aos princípios de igualdade de chances e da meritocracia veiculados pelo modelo de escola compreensiva. Por outro lado, os docentes mais "tradicionalistas" opunham-se à ação sindical, afirmando seu vínculo à seleção de alunos e à transmissão de conhecimentos acadêmicos. Eles defendiam a conservação da autoridade em sala de aula e criticavam os pedagogos. Entre esses dois grupos, uma minoria de docentes, também de oposição à greve e à ação coletiva, lançava as premissas de uma nova cultura profissional. Estes "empreendedores" aceitaram, querendo ou não, os princípios da Nova Gestão Pública e a extensão de suas responsabilidades para fora da sala de aula. Estas divergências, mais o ritmo desenfreado das reformas, contribuíram para enfraquecer o controle do trabalho pela profissão, colocando-a rapidamente em um contexto de pressão ao desempenho e de disputa interindividual.

A parir de 1997, a política "modernizadora" do governo trabalhista continuava a reforma da profissão, fortalecendo o peso da avaliação através da criação de um sistema complexo e hierarquizado de padrões, de benchmarks, e de alvos estratégicos para melhorar o desempenho. $\bigcirc$ departamento de

40 educação reestruturava as condições de trabalho e a formação dos docentes, fazendo-se mais intervencionista e diretivo. No entanto, enquanto continuava a diversificação do estatuto das escolas públicas, foram rapidamente identificados problemas na contratação e na manutenção de docentes em bairros difíceis. Ele prometeu, então, equilibrar a "pressão" aos resultados e o "apoio" aos docentes para ajudá-los a serem "bons profissionais", sem, no entanto, renunciar ao desempenho. Esta política foi consagrada em um Livro Verde intitulado Docentes. Encarar os desafios da mudança². (GLEESON; HUSBANDS, 2000). O relatório pretende revisar a carreira profissional dos docentes, instituindo um sistema de remuneração por desempenho (performance-relatedpay - PRP). Relatórios contraditórios foram redigidos pelo National Union ofTeachers (NUT), o principal sindicato de docentes. Este último tentou inclusive uma ação frente aos tribunais para obter uma revisão dos padrões associados ao desempenho, mas obteve apenas uma modificação mínima.

P PRP criou um sistema de avaliação de desempenho no qual o docente devia prestar contas aos seus superiores dos progressos concluídos pelos alunos. Ainda hoje ele deve comprovar a manutenção e o aperfeiçoamento de suas competências frente a uma série de critérios profissionais: 
resultados de testes, gestão de classe e de avaliação, atualização dos conhecimentos profissionais, eficiência ao respeitar as prescrições e a aplicação das reformas. Além disso, a carreira e a remuneração variam, dependendo se os docentes ocupam funções pedagógicas tradicionais em sala de aula (serviço mínimo) ou se eles aceitam assumir responsabilidades na escola, animar uma equipe e garantir instrução para seus colegas, ou ainda que façam reconhecer sua expertise.

Os efeitos negativos da gestão de desempenho foram denunciados por sociólogos após estudos de campo realizados nas escolas. Stephen Ball explica que um tipo de "esquizofrenia" tomou conta dos docentes que deviam, dali em diante, escolher entre trabalho de equipe e individualização, autonomia e conformidade às normas, desenvolvimento profissional e desempenho. (BALL, 2001). Ao "jogar o jogo" e ao "conformar-se com as prescrições", estes envolviam-se em diversas manipulações de informação, permitindo-thes adaptar-se aos objetivos que thes eram fixados. Sharon Gewirtz relata a forma através da qual esta nova gestão monetizou e diferenciou o valor escolar dos alunos. (GEWIRTZ, 2002). Se cada aluno equivale a um orçamento per capita para a escola, o aluno que dispõe de uma capacidade elevada ou de uma forte motivação dá segurança de bons resultados para a escola com um mínimo de investimento: ele é, portanto, lucrativo. Inversamente, o aluno que encontra dificuldades, mais frequentemente vindo de meios populares, não possui grande valor para a gestão.

\section{A leadership: diversificação das funções e recomposições de um profissionalismo de profissão}

A política do desempenho é sintomática da passagem de um profissionalismo de profissão a um profissionalismo de organização. (EVETTS, 2003). $\bigcirc$ primeiro modelo vem de uma lógica em que um grupo profissional dispõe de uma autoridade colegiada na escola e em que a confiança rege as relações entre pares. Esta postura é baseada em uma grande autonomia e em um julgamento discricionário, especialmente em relação à avaliação dos alunos. trabalho é comandado pela expressão de uma forte identidade social e por um código ético elaborado em grande parte pelos próprios profissionais. o segundo modelo corresponde a um fortalecimento do controle do trabalho 
pelos gerentes segundo uma linha de ordem hierárquica, mas também a uma divisão horizontal de funções e responsabilidades na escola. Implica, internamente, na execução de processos padrão e, externamente, em formas de controle e de avaliação da qualidade através de instrumentos (indicadores, "benchmarks") ou através de alguns profissionais (auditores, inspetores, supervisores). As tarefas e atividades profissionais dos docentes são modificadas, pois eles são chamados para diferentes ações fora da sala de aula para trabalhar em equipe com seus colegas.

Sobre a base desta diferenciação de tarefas e responsabilidades, vários postos intermediários são oficialmente reconhecidos. (GUNTER; RAYNER, 2007). O posto de "docente leader" é ocupado por profissionais experientes que estão envolvidos no aperfeiçoamento do desempenho de seus colegas ou da execução do trabalho colaborativo. Eles acompanham jovens professores e observam suas práticas pedagógicas em sala de aula. As autoridades locais recrutaram profissionais especialistas como "consultores" para a execução da estratégia nacional de alfabetização em linguagem e matemática. $\bigcirc$ Departamento de Educação criou um estatuto para professores de capacitação avançada para melhor reconhecer as funções de "conselheiro pedagógico" ou

42 as atividades exercidas pelos professores em posição de destaque. Em termos de gestão intermediária, é pedido às autoridades educacionais e aos coordenadores de disciplinas que exerçam funções de leadership. (NORMAND, 2010). $\bigcirc$ trabalho desses profissionais é definido por referenciais de competências em diferentes áreas de atuação: direção estratégica e desenvolvimento de uma disciplina escolar, controle e avaliação do ensino, gestão de equipes, disponibilização de funcionários e de recursos.

Esta nova estruturação das funções ocorreu na sequência dos relatórios de inspeção, insistindo na necessidade de um corpo intermediário com a finalidade de contribuir para a dinâmica de melhor desempenho da escola. Para apoiar essas novas funções, foram estabelecidos programas de formação pelo National College for School Leader ship, o centro de formação de quadros. $O$ posto de "coordenador" constitui outra forma de leadership: é um professor que exerce funções de tutor ou de responsável pelo treinamento de seus colegas. Ele pode também ser envolvido no cuidado com alunos portadores de necessidades especiais ou fazer o papel de "facilitador" na condução de projetos de pesquisa-ação, garantindo a coordenação entre um grupo docente e a equipe de pesquisa. Geralmente trabalha na escola, mas pode ser membro de uma 
rede de comunidades de aprendizagem (networkedlearningcommunities), que organiza a troca e a transferência de conhecimento e de competências entre diversas instituições. Por fim, existem os "inovadores", professores engajados em um grupo de aperfeiçoamento da escola ou em projetos financiados por patrocinadores, universidades ou outros parceiros. A inovação desemboca na criação de referenciais ou de guias de boas práticas postos a disposição de outros professores em nível local ou nacional.

Esta divisão do trabalho com a equipe de direção varia de uma localidade a outra, devido a uma forte diversidade do estatuto das instituições públicas, a sua oferta de serviços educativos, a seus recursos públicos e privados, e a sua participação em grandes programas nacionais ou de redes inovadoras. $O$ exercício da leadership é também alvo de críticas por parte dos pesquisadores quando se assemelha a um discurso que esconde posturas hierárquicas, funcionais e prescritivas centradas na eficiência e no desempenho. Os neoconservadores haviam concebido a leadership como o exercício de autoridade moral e de papel de empresário por parte do diretor da escola. (GRACE, 1995). O governo trabalhista ampliou esta concepção para melhor regular as práticas profissionais. $O$ controle dos professores é fortalecido pelo uso de diferentes técnicas gerenciais (BUTT; GUNTER, 2007): recompensas simbólicas e honoríficas para os melhores leaders, sistema de rotulagem e certificação de competências à leader ship, apoio aos defensores da reforma e marginalização de seus críticos. Hoje, a função de "leader ship distribuída" caracteriza as missões e as tarefas cumpridas diariamente pelos dirigentes escolares e pelos professores nos ENT (environnementnumérique de travail³). Os sociólogos são geralmente céticos em relação às possibilidades reais de transformação do meio profissional. (GUNTER, 2001, 2005; THRUPP; WILLMOT, 2003). Eles consideram que a leadership funcional e estratégica seja simplista, pois leva em conta apenas as dimensões formais das relações humanas, enquanto que interações mais informais são consideradas igualmente fundamentais para a organização do trabalho na escola. 


\section{O ingresso na profissão e na formação: um desenvolvimento profissional contínuo}

$\bigcirc$ Livro Verde sobre o desempenho também induziu mudanças significativas para a formação inicial e para o ingresso na profissão docente. Dois dispositivos foram especialmente desenvolvidos: a indução e a tutoria. A indução profissional tem por objetivo articular a formação inicial e a execução de práticas eficazes, familiarizando o jovem professor com as regras da profissão e com uma diversidade de experiências pedagógicas. Posteriormente, padrões profissionais definem as condições de promoção durante a carreira. (EVANS, 2008; MAHONY; HEXTALL, 2000). Estes padrões descrevem precisamente as habilidades e os conhecimentos que os professores devem alcançar e manter durante as cinco grandes etapas de sua carreira profissional, desde a posição de neo-titular - em que eles obtém o status de docente qualificado (Qualifiedteacher status) -, até a posição final de docente de competências avançadas (Advancedskillsteacher). Dentre os cerca de trinta critérios internos para o procedimento de avaliação, é esperado que o professor comece de maneira firme, eficaz e pertinente no seu "desenvolvimento profissional contí-

44 nuo" e no de seus colegas. (DEROUET; NORMAND, 201 lb). Esta concepção da formação é justificada em nome do desempenho. (MALET; BRISARD, 2005). A formação deve fazer-se ao longo da vida profissional, estando próxima das situações vividas no lugar de trabalho. De acordo com as normas oficiais, este desenvolvimento profissional deve nutrir-se dos resultados da pesquisa em educação sobre a eficácia pedagógica e apoiar-se no domínio de saberes não limitados à especialização disciplinar.

No domínio da sociologia houve críticas em relação a uma concepção do "profissionalismo", que projeta uma imagem tipo ideal da organização escolar longe das práticas concretas dos docentes. (EVANS, 2008; OZGA, 1988). Além de sua conciliação cotidiana com prescrições e múltiplas tarefas, muitos professores adotam atitudes e esquemas cognitivos que certificam habilidades ignoradas por estas abordagens gerenciais. Estes aspectos comportamentais e intelectuais de um trabalho que se realiza, primeiramente em micro-situações, entram em tensão com as regras processuais e behavioristas consecutivas à implementação de padrões profissionais e à adoção de boas práticas. Os sociólogos mostram, assim, que os registros emocionais e éticos, e a forma de ser no trabalho, fogem de uma definição tão restrita. Para além das 
dimensões funcionais e distribuídas que regulam a atividade pedagógica e a formação na escola, existem registros de motivação, de crença e de avaliação implícita, bem como dos conhecimentos tácitos que, embora sejam ignorados pela administração, constituem uma característica essencial do exercício da profissão.

\section{França: em direção a uma Nova Gestão Pública na educação?}

Se, na França, a cultura do desempenho é hoje a palavra de ordem da alta administração da Educação Nacional, muitos quadros intermediários e muitos diretores são ainda reticentes em endossar uma postura gerencial e ao utilizar instrumentos de avaliação. (BARRĖRE, 2006). Na escola os professores são muito comprometidos com sua liberdade pedagógica e opõem-se ao fortalecimento do controle hierárquico. Contudo, o modelo de burocracia profissional que separa funcionalmente a administração, a vida escolar e a sala de aula, de acordo com missões e estatutos altamente diferenciados, é hoje novamente posto em questão. Enquanto o contexto da crise orçamental acentua as tensões, o ministério opera mudanças prudentes apoiando-se na reforma geral da administração pública. A ideia de que alguns quadros (dirigentes e diretores) fossem daquele momento em diante remunerados pelo desempenho foi gradualmente instalada. Da mesma forma, foram projetadas mudanças nas formas de avaliação dos professores que dariam mais poder aos diretores. Alguns deles poderiam ser recrutados de acordo com perfis de competências. A criação do "prefeito dos estudos", além de sua mística "napoleônica", instituiu uma nova função de coordenação transversal, modificando a tradicional divisão de funções e responsabilidades nas escolas mais desfavorecidas. A reforma da formação de professores, fortemente criticada por sua falta de ambição e sua visão utilitarista, dissemina implicitamente a ideia de desenvolvimento contínuo.

As atuais reformas, que mais ou menos se baseiam nos princípios da Nova Gestão Pública, deveriam beneficiar mais os diretores do que os inspetores. Como parte de um reforço da autonomia local da escola, são os primeiros que poderiam dispor de margens de manobra. Ao contrário, os inspetores sentem-se, ao longo do tempo, ameaçados, pois correm o risco de perder um importante poder controlador, especialmente no domínio da avaliação. Os 
sindicatos também estão divididos entre os reformistas, favoráveis a diversificação pedagógica e a redefinição da profissão, e os contestadores, contra a introdução de uma lógica neoliberal na educação pública. Deve-se ter em conta estas relações de força para considerar as transformações por ocorrer na profissão. Mesmo na Inglaterra a resistência dos professores teve consequências. Após tentativas frustradas de boicote às avaliações nacionais, os sindicatos obtiveram um alívio da carga de trabalho e da pressão ao desempenho. (JONES, 2009). O direito a um melhor equilíbrio entre vida profissional e vida doméstica thes foi reconhecido.

Nada permite afirmar hoje que uma evolução à inglesa pudesse acontecer na França, mesmo se alguns elementos de reforma pareçam emprestados da política da Terceira Via, especialmente no setor de educação prioritária. De acordo com a classificação das reformas da Nova Gestão Pública, elaborada por Christopher Pollitt, a Inglaterra pertence à categoria dos "concorrentes". O país dá importância à competição no setor público e promove os quase-mercados, como os contratos em grande escala, as nomeações de funcionários por contratos e sua remuneração por desempenho, assim como uma redução de fronteiras entre o público e o privado. A França encontra lugar entre os 46 "modernizadores". Os elaboradores de políticas franceses acreditam no papel do Estado, mas defendem também a necessidade de mudanças importantes na maneira pela qual os sistemas administrativos são organizados, o que passa, de acordo com eles, por reformas de orçamento centradas na medida de resultados e de desempenho, na descontração da rigidez estatutária nos serviços públicos, maior descentralização ou desconcentração dos ministérios, uma melhoria da qualidade de serviços públicos. $\bigcirc$ mercado e a concorrência exercem um papel menor, assim como as lógicas de privatização.

Existem, portanto, diferenças nas trajetórias adotadas por diferentes países para reformar seu sistema educativo. Certamente, o controle sobre a profissão docente se fortalece em virtude de técnicas e dispositivos que visam submeter os professores a uma obrigação de resultados. No entanto, o equilíbrio entre autonomia profissional e normalização de práticas, a pressão ao desempenho, as formas de coordenação no trabalho variam fortemente. Segundo a ideologia do momento, a história das instituições educativas, as capacidades de ação coletiva dos sindicatos, as transformações do modelo profissional revelam configurações nacionais bastante diferentes. Apesar de tudo, a Nova Gestão Pública põe à prova a profissão docente, assim como 
a organização administrativa, planificada e hierárquica, na qual um grupo profissional dependia de um único estatuto para cumprir suas atividades. Na França, os professores ganharão autonomia profissional ou serão tributários de um processo de desprofissionalização? A liberdade pedagógica, a qual frequentemente evocam, deveria ser enquadrada por novas normas que regessem suas atividades de trabalho. É possível que referenciais de competências redefinam suas atividades e seu desenvolvimento de carreira. $\bigcirc$ papel crescente do diretor no controle educacional e a retirada gradual do controle disciplinar poderiam perturbar o equilíbrio tradicional entre o pedagógico e o administrativo. Formas de coordenação transversal e de funções intermediárias, impostas pelos desenvolvimentos de avaliação e ENTs, poderiam redistribuir funções e responsabilidades. Estas evoluções constituirão um desafio maior para os professores que fizeram sua carreira no antigo modelo profissional, mas elas deverão ser aceitas pela nova geração que é mais receptiva à mudança e à inovação. (RAYOU; VAN ZANTEN, 2004). Alguns professores encontrarão, também, possibilidades de autonomia nas iniciativas que lhes foram recusadas até o momento. Outros terão o sentimento de declínio da profissão e de desmantelamento profissional. No entanto, esta virada neo-gerencial que inicia uma mudança profunda da função pública do Estado, parece irreversível, mesmo que permaneça fortemente contestada.

\section{Notas}

1 Lei orgânica relativa às leis de finanças. No original: Loi organique relative aux lois de finances.

2 No original: Enseignants. Faire face aux défis du changement.

3 Plataforma virtual de trabalho desenvolvida pelo Ministério de Educação Nacional Francês.

\section{Referências}

BALL, S. J. Performativities and fabrications in the education economy: towards the performative society. In: GLEESON, D., HUSBANDS, C. (Eds.). The performing school. Routledge: London, 2001 . p. $210-225$.

BARRERE, A. Sociologie des chefs d'établissement. Les managers de la République.Puf: Paris, 2006. 
BEZES, P. Réinventer I'État. Les réformes de l'administration francaise (1962-2008). Puf: Paris, 2009.

BUTT, G., GUNTER, H. Modernizing schools: people, learning and organizations. Continuum: London, 2007.

CLARKE, J., GEWIRTZ, S., MC LAUGHIN, E. New managerialism: New Welfare? Sage: London, 2000.

DEROUET, J. L., NORMAND, R. Caesars and Rubicons. The hesitations of French Policy Makers in identifying a Third Way in Education and Training. Journal of Educational Administration and History, v. 43, n. 2, p. 141-163, $2011 \mathrm{la}$.

DEROUET, J. L., NORMAND, R. (Eds.). Évaluation, développement professionnel et organisation scolaire. Revue Française de Pédagogie, 174, p. 520, $2011 \mathrm{~b}$.

DUBET, F. Le travail des sociétés. Seuil: Paris, 2009.

EVANS, L. Professionalism, Professionality, and the Development of Education Professionnals. British Journal of Education Studies, v. 56, n. 1, p. 20-38, 2008.

EVETTS, J. The sociological analysis of professionalism: occupational change in the modern 48 world. International Sociology, v. 18, n. 2, p. 395-4 15, 2003.

FAUCHER-KING, F., LE GALES, P. Les gouvernements new labour. Le bilan de Tony Blair et de Gordon Brown. Presses de Sciences Po: Paris, 2010.

GEWIRTZ, S. The managerial school: post-welfarism and social justice in education. Open University Press: Buckingham, 2002.

GLEESON, D., HUSBANDS, C. (Eds.). The performing school. Managing, teaching and learning in a performance culture. Routledge: London, 2000.

GRACE, G. School leadership: beyond educational management. An essay in policy scholarship. Falmer: London, 1995.

GUNTER, H. Leaders and Leadership in Education. Paul Chapman: London, 2001.

GUNTER, H., RAYNER, S. Modernizing the schoolworkforce in england: Challenging Transformations and Leadership. Leadership, v. 3. n. 1, p. 47-64, 2007.

JONES, K. An English Vernacular: Teacher Trade Unionism and Educational Politics 19702007. In: Gewirtz, S., Mahony, P., Hextall, I., Cribb, A. (Eds.). Changing teacher 
professionalism. International Trends, Challenges and Ways Forward. Routledge: London, 2009. p. 54-64.

MAC AN GHAlLL, M. Teachers' Work: curriculum restructuring, culture, power and comprehensive schooling. British Journal of Sociology of Education, v. 13, n. 2, p. 177-199, 1992.

MAHONY, P., HEXTALL, I. Reconstructing teaching standards, Performance and accountability. Routledge Falmer: London, 2000.

MALET, R., BRISARD, E. (Eds.). Modernisation de l'école et contextes culturels. Des politiques aux pratiques en France et en Grande-Bretagne. L'Harmattan: Paris, 2005.

NORMAND, R. Le leadership dans l'établissement scolaire. Un nouveau partage des responsabilités entre chef d'établissement et enseignants. Administration \& Éducation, v. 127, n. 3, p. 188-194, 2010.

Gouverner la réussite scolaire. Une arithmétique politique des inégalités. Peter Lang/Presses de l'École Normale Supérieure: Berne, 2011.

OZGA, J. (Ed.) Schoolwork: approaches to the labour process of teaching. Open University Press, Milton Keynes: Buckingham, 1988.

POLLITT, C., BOUCKAERT, G., 2004. Public management reform: A Comparative Analysis.

2nd. Edition. Oxford University Press: Oxford, 2004.

RAYOU, P., van ZANTEN, A. Enquête sur les nouveaux enseignants. Changerontills l'école? Bayard: Paris, 2004.

THRUPP, M., WILLMOTT, R. Education management in managerialist times, beyond the textual apologists. Open University Press: Buckingham, 2003. 


\author{
Prof. Dr. Romuald Normand \\ Maître de Conférences-HDR \\ Professor Associado \\ Laboratório Triangle (UMR 5206) \\ Escola Normal Superior de Lyon \\ Instituto Francês de Educação \\ E-mail | romuald.normand@ens-lyon.fr
}

Texto traduzido por Luiza de Souza Hypolito E-mail | luizahypolito@gmail.com Revisão técnica do Prof. Dr. Álvaro Moreira Hypolito E-mail | alvaro.hypolito@gmail.com

Recebido 6 ago. 2013 Aceito 14 out. 2013 